\title{
Effect of mold temperature on interfacial welded strength and outer shell laminate strength of CF/PA6 composites manufactured by press and injection hybrid molding
}

\author{
K. Tanaka, Y. Kondo \& T. Katayama \\ Department of Biomedical Engineering, Doshisha University, Japan
}

\begin{abstract}
The press and injection hybrid molding system is a novel molding technology with the combination of press molding and injection molding, and is expected for the mass production of FRTP (Fiber Reinforced Thermoplastics) which have complicated shapes. The hybrid FRTP structure consists of the following two structures: the outer shell laminate structure that is molded by the press molding using continuous fiber, and the rib structures that are molded by the injection molding using short or long fibers. In a previous study, the hybrid composite has been reported to fracture at the welded interface between the laminate and injected material. The method, in which outer shell laminate penetrates into the rib structures, was developed to increase the interfacial welded strength. However, the continuous fiber of outer shell laminate waves at the welded interface and may lead to reduction in mechanical properties. Therefore, it is necessary to clarify the reduction in the strength of outer shell laminate. In this study, the effects of mold temperature on the mechanical properties were evaluated by T-shaped specimens for interfacial welded strength and by in-plain tensile tests for the strength of outer shell laminate. As the mold temperature becomes higher, the penetrated height of continuous fiber into a rib becomes higher and higher interfacial welded strength is obtained.

Keywords: press and injection hybrid molding, carbon fiber reinforced thermoplastics, CFRTP, interfacial welded strength, rib, outer shell laminate strength.
\end{abstract}




\section{Introduction}

In the automotive industry, from the point of the regulation of $\mathrm{CO}_{2}$ exhausted from automobiles, reduction of the mass of automotive bodies has become more important than ever. In particular, automotive weight lightening by using Carbon Fiber Reinforced Thermoplastics (CFRTP), which has the advantages of highspecific strength and high-specific stiffness, has been receiving a lot of attention $[1,2]$. For the production methods of CFRTP parts there are many molding process, such as press molding, injection molding and so on. Molding process and materials, especially fiber length, will be chosen to satisfy the required mechanical properties as the fiber length used for CFRTP and fiber content affect the mechanical properties and formability of CFRTP [3]. CFRTP products manufactured by compression molding using continuous fiber have high stiffness [4], but can't be used for complicated structure due to a poor formability. On the other hand, products manufactured by injection molding using short or long discontinuous fiber, which can mold complicated structures, have lower stiffness than compression molded products $[5,6]$. In order to make up for each disadvantage, the press and injection hybrid molding, which combines an injection unit with a press machine, has been developed [7-9]. The hybrid molding system can mold CFRTP products with high strength and high stiffness outer shell laminate of continuous fiber reinforced composite and complicated rib structures of short or long fiber reinforced plastics. The hybrid molded product was reported to fracture at the interface between the outer shell laminate part and injected part $[10,11]$. The method, in which outer shell laminate penetrates into the rib structures, was developed to increase the interfacial welded strength [12]. Although the penetration of continuous fiber of outer shell laminate into rib structure may lead to the reduction of in-plain mechanical properties due to waviness of the continuous fiber [13], the reduction of the outer shell laminate strength has not been clarified yet. In this study, the effect of mold temperature on the mechanical properties of CF/PA6 hybrid composites manufactured by the press and injection hybrid molding was investigated. Their mechanical properties were evaluated by T-shaped specimens for the interfacial welded strength and by in-plain tensile tests for the strength of outer shell laminate with a help of the non-contact strain analysis system.

\section{Materials and experimental procedures}

\subsection{Materials}

Carbon fiber non-crimp fabric $\left(\mathrm{NCF},\left[0^{\circ} / 90^{\circ}\right], 300 \mathrm{~g} / \mathrm{m}^{3}\right.$, Toho Tenax) was used for the reinforcement of laminated $\mathrm{CF} / \mathrm{PA} 6$ composites, which will be used for outer shell laminates of hybrid molding. Non-woven fabric sheet (Prototype, Kuraray Co., Ltd., $50 \mathrm{~g} / \mathrm{m}^{2}$ ) of polyamide 6 (PA6, 1013B, Ube industries, melting point $225^{\circ} \mathrm{C}$ ) is used for the matrix of the laminated $\mathrm{CF} / \mathrm{PA} 6$ composites. The same 
polyamide 6 pellets were used for the materials of injection molding. The press and injection hybrid molding machine (Sato Tekko) was used for manufacturing the CF/PA6 laminate and the hybrid CFRTP composites. The CF/PA6 laminate was molded with a plate mold at $260^{\circ} \mathrm{C}$ and held at $2.0 \mathrm{MPa}$ pressure for $180 \mathrm{sec}$ to impregnate resin to $\mathrm{NCF}$. The fiber volume fraction of the laminate was set for $50 \%$ and its thickness was $2.0 \mathrm{~mm}$.

\subsection{Press and injection hybrid molding}

Schematic drawing of the press and injection hybrid molding system is shown in Fig. 1. Table 1 shows the molding parameters for the press and injection molding. After the laminated CF/PA6, which was heated in an oven at $280^{\circ} \mathrm{C}$, was placed inside the mold, the laminate was press-molded at constant press pressure of $25 \mathrm{MPa}$ and PA6 was injected into space for the ribs. A molded product manufactured by the press and injection hybrid molding is shown in Fig. 2. Three levels of temperature for press mold, $130^{\circ} \mathrm{C}, 160^{\circ} \mathrm{C}$ and $190^{\circ} \mathrm{C}$, were used to understand the influence of mold temperature on the penetration behaviour and the tensile strength of outer shell laminate.



Figure 1: Press and injection hybrid molding system.

Table 1: Molding parameters of the hybrid molding.

\begin{tabular}{ccc}
\hline \multirow{3}{*}{ Injection } & Temperature $\left[{ }^{\circ} \mathrm{C}\right]$ & 260 \\
\cline { 2 - 2 } & Speed $[\mathrm{mm} / \mathrm{s}]$ & 60 \\
\cline { 2 - 2 } & Pressure $[\mathrm{MPa}]$ & 124 \\
\hline \multirow{3}{*}{ Press } & Pressure $[\mathrm{MPa}]$ & 25 \\
& & 130 \\
& Temperature $\left[{ }^{\circ} \mathrm{C}\right]$ & 160 \\
& & 190 \\
\hline
\end{tabular}






(a) Rib structure side.

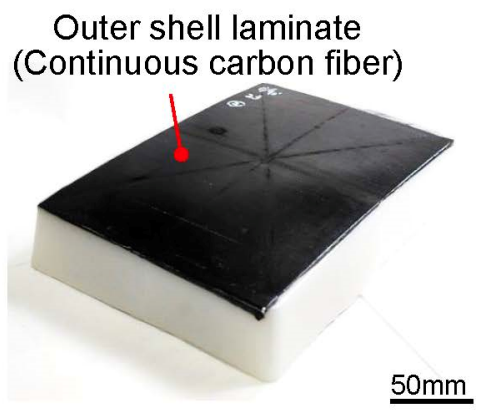

(b) Shell structure side.

Figure 2: Molded product manufactured by the press and injection hybrid molding.

\subsection{Tensile tests}

In order to evaluate the welded interface between outer shell laminate and injected ribs, penetrated height, which was defined as the average height in the width direction shown in Fig. 3, was measured. The interfacial welded strength was measured by tensile tests of T-shaped specimens. T-shaped specimens were cut out from the hybrid molded products as shown in Fig. 4(a). The dimensions of the specimen were $35 \mathrm{~mm}$ in length (orthogonal to rib direction) and $15 \mathrm{~mm}$ in width. Aluminum tab was glued to the outer shell laminate using an epoxy adhesive and the test specimen was fixed to universal material testing machine (5566, Instron, U.S.A.) as shown in Fig. 4(a). The tensile tests of T-shaped specimens were conducted at a cross speed of $0.017 \mathrm{~mm} / \mathrm{sec}$ and at the room temperature. In order to evaluate the effect of penetration on in-plain tensile strength of outer shell laminate, tensile tests of outer shell laminate were conducted. The in-plain tensile test specimen of outer shell laminate was cut out from the hybrid molded products as shown in Fig. 4(b). For the references, tensile tests of laminated CF/PA6 were also conducted. The dimensions of the specimen were $154 \mathrm{~mm}$ in length (orthogonal to rib direction) and $15 \mathrm{~mm}$ in width. Aluminum tab was glued to the



Figure 3: Schematic drawing of penetrated height. 
both ends of the specimen using an epoxy adhesive. The in-plain tensile tests were conducted by the tensile testing machine (Auto graph, Shimazu) at a cross speed of $0.033 \mathrm{~mm} / \mathrm{sec}$ at the room temperature. A non-contract strain analysis system (ARAMIS $^{\circledR}, \mathrm{GOM} \mathrm{mbH}$ ) was used to understand the strain distribution of the specimens during the tensile tests.


(a) T-shaped specimen and its tensile test.



(b) Specimen of outer shell laminate and its tensile test.

Figure 4: $\quad$ Schematic drawing of two types of tensile tests.

\subsection{Measurement of temperature history of laminated CF/PA6}

K-type thermocouples were used to measure the temperature history of the outer shell laminate to evaluate the effect of mold temperatures on the temperature of laminated CF/PA6 as shown in Fig. 5. The measured point is the place where the injection materials will be injected to form ribs. The temperature history was measured from the period when the outer shell laminate was heated at $265 \pm 5^{\circ} \mathrm{C}$ in an oven to the period when the outer shell laminate was cooled to $225^{\circ} \mathrm{C}$, which is the melting point of PA6, in the mold. 


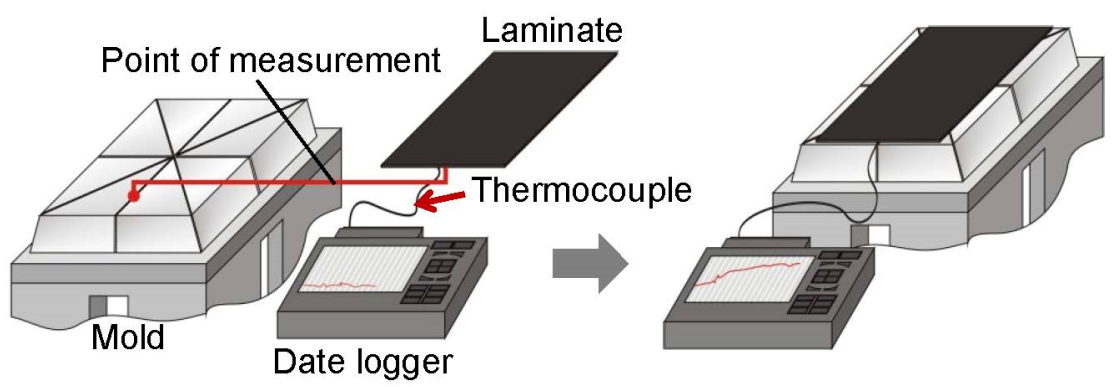

Figure 5: Temperature history of laminate.

\section{Results and discussion}

Figure 6 shows the interfacial welded strength obtained by the tensile tests of Tshaped specimens. The interfacial welded strength of the specimen at $130^{\circ} \mathrm{C}$ and $160^{\circ} \mathrm{C}$ of mold temperature is less than that of the specimen at $190^{\circ} \mathrm{C}$ of mold temperature. The highest interfacial strength, $19.2 \pm 1.0 \mathrm{MPa}$, is obtained for the specimen at $190^{\circ} \mathrm{C}$ of mold temperature. Fig. 7 shows the penetrated height of continuous fiber into a rib for T-shaped specimens. The penetrated height of the specimen molded at $190^{\circ} \mathrm{C}$ is higher than that of the specimen at $130^{\circ} \mathrm{C}$ and $160^{\circ} \mathrm{C}$ of mold temperature. Fig. 8 shows the magnified cross-sectional view of the specimens at $130^{\circ} \mathrm{C}$ and $190^{\circ} \mathrm{C}$ of mold temperature at the interface between rib and outer shell laminate. The specimen molded at $190^{\circ} \mathrm{C}$ of mold temperature had higher penetrated height than that at $130^{\circ} \mathrm{C}$ of mold temperature, and waviness of continuous fiber in outer shell laminate is observed at the specimen at $190^{\circ} \mathrm{C}$ of mold temperature. Figure 9 shows the tensile strength of outer shell laminate molded at each temperature. As the mold temperature become higher, the tensile strength of the outer shell laminate becomes lower. The in-plain tensile strength of the outer shell laminate specimen at $190^{\circ} \mathrm{C}$ of the mold temperature becomes $37.9 \%$ of the tensile strength of laminated CF/PA6. Fig. 10 shows strain distribution of the outer shell laminate specimens just before the final fracture in the tensile test. The strain concentration at the root of the rib structure of the specimen at $190^{\circ} \mathrm{C}$ of mold temperature as shown in Fig. 10 (b) is greater than that at $130^{\circ} \mathrm{C}$ of mold temperature. Figure 11 shows the temperature history of outer shell laminates. While the temperature of the outer shell laminate at $130^{\circ} \mathrm{C}$ of mold temperature decreased sharply, that at $190^{\circ} \mathrm{C}$ decreased gradually. Due to the slow decrease of the temperature at $190^{\circ} \mathrm{C}$, outer shell laminate had the formability to penetrate into the rib structures during the press molding process and waviness of continuous fiber is occurred. This is considered to be the reason for the higher interfacial welded strength between the injection molded rib structures and the lower tensile strength of the outer shell laminate specimen at $190^{\circ} \mathrm{C}$ of mold temperature. 




Figure 6: Interfacial welded strength by the tensile tests of T-shaped specimens.



Figure 7: $\quad$ Penetrated height of T-shaped specimen. 




(a) $130^{\circ} \mathrm{C}$.

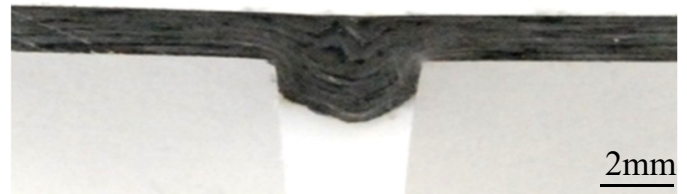

(b) $190^{\circ} \mathrm{C}$.

Figure 8: $\quad$ Magnified cross-sectional view of T-shaped specimens.



Figure 9: $\quad$ Tensile strength of laminated CF/PA6 and the outer shell laminate. 




Figure 10: Strain distribution of the outer shell laminate specimen just before the final fracture.

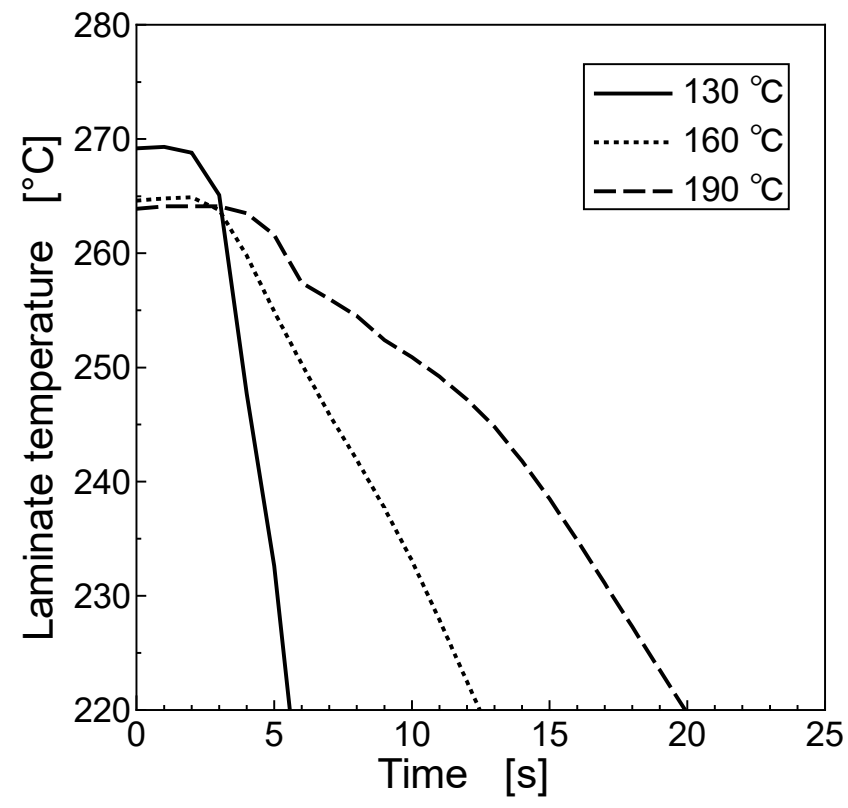

Figure 11: Temperature history of the outer shell laminate. 


\section{Conclusions}

CF/PA6 hybrid composites were manufactured by the press and injection hybrid molding at different mold temperatures. Their mechanical properties were evaluated by T-shaped specimens for the interfacial welded strength and in-plain tensile strength of outer shell laminate. The investigation yielded the following conclusions.

1. As the mold temperature becomes higher, the penetrated height of continuous fiber into a rib becomes higher. Highest interfacial welded strength of $19.2 \pm 1.0$ $\mathrm{MPa}$ is obtained at the mold temperature of $190{ }^{\circ} \mathrm{C}$.

2. As the penetration of a continuous fiber into a rib structure becomes higher, the in-plain tensile strength of outer shell laminate becomes lower due to the waviness of continuous fiber of outer shell laminate. The in-plain tensile strength of the outer shell laminate at $190{ }^{\circ} \mathrm{C}$ of the mold temperature becomes $37.9 \%$ of the tensile strength of laminated CF/PA6.

\section{References}

[1] Ishikawa. T, Overview of Carbon Fiber Reinforced Composites (CFRP) Applications to Automotive Structural Parts, -Focused on Thermoplastic CFRP-, Journal of the Japan Society for Precision Engineering, Vol. 81, No. 6, pp. 489-493, 2015.

[2] Yamane. M, Technical Collection of Carbon Fiber Reinforced Thermoplastics, Science \& Technology, pp. 16-28, 2015.

[3] Thomason. JL \& Vlug. M. A, Influence of fibre length and concentration on the properties of glass fibre-reinforced polypropylene: 4. Impact properties, Composites, Part A, pp. 277-288, 1997.

[4] Fujii. M, Thermoplastic composite. TEXXES thermoplastic materials, Reinforced Plastics, Vol. 38, No.4, pp. 131-137, 1992.

[5] Ogawa. T, Mima. M and Taya. N, Change of fiber length in injection molding of carbon fiber reinforced nylon 66, Seikei-Kakou, Vol. 7, No. 5, pp. 315-320, 1995.

[6] Sakata. S, Ashida. F \& Tanaka. R, Hierarchical stochastic homogenization analysis of a short-fiber reinforced composite material considering a nonuniform microscopic random variation, Transactions of the Japan Society of Mechanical Engineers Series A, Vol. 77, No. 783, pp. 1945-1955, 2011.

[7] Harte. AM \& Mc Namara. JF, Overinjection of thermoplastic composites, Journal of Materials Processing Technology, Vol. 182, No. 1-3, pp. 12-20, 2007.

[8] Fiorotto. M \& Lucchetta. G, Experimental investigation of a new hybrid molding process to manufacture high-performance composites, International journal of material forming, Vol. 6, No. 1, pp. 179-185, 2013. 
[9] Aurrekoetxea. J, Castillo. G, Cortes. F, Sarrionandia. MA \& Urrutibeascoa. I, Failure of multimaterial fusion bonding interface generated during overinjection molding/thermoforming hybrid process, Journal of Applied Polymer Science, Vol. 102, No. 1, pp. 261-265, 2006.

[10] Key. CT, Garnich. MR \& Hansen. AC, Progressive failure predictions for rib-stiffened panels based on multicontinuum technology, Composite Structures, Vol. 65, Issues 3-4, pp. 357-366, 2004.

[11] Stickler. PB \& Ramulu. M, Investigation of mechanical behavior of transverse stitched T-joints with PR520 resin in flexure and tension, Design and Manufacturing of Composite Structures, Vol. 52, Issues 3-4, pp. 307314, 2001.

[12] Tanaka. K, Fujita. Y \& Katayama. T, Press and injection hybrid molding of glass fiber reinforced thermoplastics, WIT Transactions on Engineering Sciences, Vol. 90, pp. 225-232, 2015.

[13] Shams. S \& Elhajjar. RF, Investigation into the effects of fiber waviness in standard notched composite specimens, CEAS Aeronaut J, Vol. 6, pp. 541$555,2015$. 